\title{
Book Review \\ Berezkin, V.G., N.A. Izmailov i M.S. Shraiber: Otkrytie Tonkosloinoi Khromatografii (N.A. Izmailov and M.S. Shraiber: The Discovery of Thin-Layer Chromatography), Moscow: GEOS, 2007, 128 pp.
}

DOI: $10.1134 / \mathrm{S} 1061934809050177$

This book prepared by Doctor of Chemistry, Professor Victor Grigor'evich Berezkin was published just in the time. This is not only because we are celebrating the 70th anniversary of the discovery of thin-layer chromatography (TLC) but also because the active development and expansion of TLC have to a significant extent determined the present-day renaissance of this method. International symposia on TLC are organized every year and an international edition "Journal of Planar Chromatography" (Budapest) is published.

"This method holds the destiny of the study in its arms," Berezkin opened his monograph with this quote from I.P. Pavlov, which allowed the author to go back to the roots of thin-layer chromatography and follow its evolution from the discovery to the present day.

The monograph presents the whole text of the first paper by N.A. Izmailov and M.S. Shraiber on TLC, "A drop-chromatographic method of analysis and its application to pharmacy," which was written in Kharkov in the physicochemical laboratory of the Ukrainian Institute of Experimental Pharmacy and published in the journal Farmatsiya in 1938. The main task of this institute in those years was the refinement of methods for the quality control of pharmaceutical products. The book also contains the translation of the first paper on TLC into English, which was made while preparing the paper for publication in one of the international journals in 1995. As in M.S. Tsvet's first work on column chromatography, the test objects in this work on TLC were natural substances (tinctures of cinchona, black cherry, rhubarb, mint, May lily, pepper, valeriana, etc).

It is important that N.A. Izmailov and M.S. Shraiber are the authors of not only TLC chromatography but also of its particular versions: frontal and elution circular TLC.

Berezkin in his monograph presents the biographies of the creators of TLC, professors Nikolai Arkad'evich Izmailov and his graduate student Mariya Semenovna Shraiber; memories of the Professor of Moscow State University Victoriya Nikolaevna Izmailova, the daughter and student of N.A. Izmailov; and M.S.Shraiber's paper about the discovery of thin-layer chromatography published in 1972 in the journal Chromatography and in the monograph Uspekhi Khromatografii (Advances in Chromatography, Moscow: Nauka, 1972). This allows the reader to feel the atmosphere of the period in which TLC was created.

All these data are inaccessible for the wide audience of chromatographers; they are of interest both for the history of the development and progress of chromatography and for understanding the basics of TLC.

It is interesting that V.G. Berezkin's monograph under review describes the results of an experimental reproduction of the work of researchers from Kharkov on similar objects in the 21st century, using TLC plates from the Merc Corporation. This was done at the Topchiev Institute of Petrochemical Synthesis of the Russian Academy of Sciences with the direct participation of the author of this monograph and I.I. Ashrapova, for whom it was part of the work for her B.S. degree. The qualitative assessment of the individuality of pharmaceuticals was done by the number of separated zones, their color and alteration sequence while obtaining planar ultrachromatograms.

In the epilogue, the author notes the main directions of the further evolution of TLC.

The words of Nobel Prize Winner A. Szent-Györgyi that to study means that you see the same as everybody saw but think as nobody else has thought, presented in the book under review can equally be applied to V.G. Berezkin, who made an interesting chemical and historical study.

The design of the book is attractive; it contains color illustrations on circular TLC chromatograms, is supplied with bibliographic references, and will undoubtedly be popular among the readers working in chromatography and physicochemical separation methods, as well as among those interested in the history of Russian science. 